\title{
Obsessive-compulsive symptoms in neurologic disease: a review
}

\author{
M.S. George, J.A. Melvin and C.H. Kellner \\ Departments of Neurology, and Psychiatry and Behavioral Sciences, Medical University of \\ South Carolina, 171 Ashley Avenue, Charleston, SC 29425-0742, USA
}

Correspondence: Dr M.S. George, Senior Staff Fellow, NIMH, Bldg 10, Rm 3N212, 9000 Rockville Pike Road, Bethesda, MD 20892, USA

\begin{abstract}
Obsessive-compulsive disorder (OCD) is an increasingly recognized disorder with a prevalence of 2-3\% (Robins et al., 1984). Once thought to be psychodynamic in origin, $O C D$ is now generally recognized as having a neurobiological cause. Although the exact pathophysiology of OCD in its pure form remains unkown, there are numerous reports of obsessive-compulsive symptoms arising in the setting of known neurological disease. In this paper, we review the reported cases of obsessive-compulsive symptoms associated with neurologic diseases and outline the known facts about the underlying neurobiology of OCD. Finally, we synthesize these findings into a proposed theory of the pathophysiology of $\mathrm{OCD}$, in both its pure form and when it accompanies other neurological illness.
\end{abstract}

\section{INTRODUCTION}

Sigmund Freud in his legendary case, The Rat Man, described a patient with obsessive-compulsive symptoms. Freud speculated that these symptoms arose from some underlying neurotic conflict (Freud, 1959). However, OCD has proven to be refractory to individual psychotherapy (Jenike et al., 1986). Within the past decade substantial evidence has emerged that OCD can be effectively treated with behavioral therapy and potent new serotonergic agents. Concurrently there has been a resurgence of interest in the underlying neurobiology of this interesting disorder.

It is likely that patients who suffer from OCD symptoms represent a spectrum of diseases, much as the symptoms of parkinsonism can arise from Parkinson's disease (idiopathic) or other brain pathology. In one form, OCD is idiopathic, has a marked genetic component, and is sometimes associated with tics or Gilles de la Tourette's syndrome. Other patients with OC symptoms suffer from various neurologic and metabolic illnesses (symptomatic OCD). The literature reports of OCD or obsessive-compulsive symptoms in neurologic diseases are examined below. The underlying pathophysiology of OCD is explored in light of these associations and case reports.

\section{DESCRIPTION OF OCD}

As described by DSM III-R, obsessive-compulsive disorder occurs in patients with recurrent obsessions or compulsions severe enough to cause marked distress and interference with their normal routine (APA, 1987). Obsessions are persistent ideas, thoughts, impulses, or images that are intrusive and senseless. The person recognizes that the obsessions stem from his own mind and are not imposed from without. Commonly, these obsessions consist of repetitive thoughts of violence, contamination or doubt. Compulsions are repetitive, purposeful and intentional behaviors that are often performed in response to an obsession. The patient normally recognizes that this behavior is excessive or unreasonable. Compulsions commonly involve handwashing, counting, checking, or touching. As a person attempts to resist a compulsion, a sense of mounting inner tension arises.

\section{OBSESSIVE-COMPULSIVE SYMPTOMS ASSOCIATED WITH MASS LESIONS OR INFARCTS}

What areas of the brain are important in regulating this abnormal behavior? To begin to answer this question one can study the case reports of OCD patients who had concommitant brain tumors or infarcts-clear evidence of focal CNS damage that might explain the OCD behavior. There are several reported cases of patients who developed obsessive-compulsive symptoms and were later found to have cerebral tumors. Brickner et al. (1940) described patients with temporal and frontal lobe tumors and seizures who developed obsessive-compulsive symptoms. Seibyl et al. (1989) recently reported an OCD patient with
Behavioural Neurology . Vol 5 . 1992 
a right frontal meningioma. A patient with a frontal callosal tumor developed obsessive-compulsive symptoms consisting of excessive writing (Cambier et al., 1988). Thus, tumors of the frontal or temporal lobes can sometimes produce OC symptoms.

The same is true for infarcts and atrophy. Tonkonogy and Barriera (1989) described a patient with progressive right-frontal lobe and bilateral caudate atrophy who had fears of contamination and compulsive hand-washing. Weilburg et al. (1989) reported a patient with obsessivecompulsive disorder who, on MRI scan, had a unilateral left-sided abnormality in the head of the caudate nucleus and putamen. This was accompanied by EEG slowing. The presumed etiology of this abnormality was ischemia secondary to perinatal anoxia. McKeon et al. (1984) described four cases of obsessive-compulsive disorder following head injury. Hillbom (1960) described a series of closed head injury patients who later developed OCD. Neither of these latter two studies found localizable brain pathology on cranial CT scans.

\section{OBSESSIVE-COMPULSIVE SYMPTOMS FOLLOWING INFECTIONS}

Infections directly or indirectly involving the basal ganglia have been reported in association with obsessive compulsive behavior. The most notable examples are the Von Economo's encephalitis cases of the 1920s and 1930s (Jellife, 1929). Schilder (1938) described several patients recovering from this encephalitis of unknown etiology. During recovery, patients developed obsessions and compulsions accompanied by various movement disorders. They had facial rigidity and mask-like faces with accompanying flexor rigidity in the arms. This led Schilder (1938) to speculate that "it is obvious that the organic disease of the central nervous system is an indispensable factor in the genesis of the psychic symptoms which have been mentioned". In looking at the spectrum of obsessive compulsive disorder, Schilder speculated that approximately one-third of OCD patients had a structural brain etiology. In another third there was a strong hint of an organic background and in the final third there was an unknown cause of the OCD symptoms. Wohlfart et al. (1961) reported a case of compulsive shouting (klazomania) that was associated with oculogyric spasms in a patient who had suffered epidemic encephalitis. The shouting attacks lasted an hour and were accompanied by a normal EEG.

Recently, Swedo et al. (1989a) interviewed rheumatic fever patients with or without Sydenham's chorea. Sydenham's chorea is a movement disorder which follows rheumatic fever (10-30\%) presumably when anticaudate antibodies are formed (Husby et al., 1976). When compared with patients who only had rheumatic fever, the
Sydenham's chorea patients scored significantly higher on criteria for obsessive-compulsive disorder. The authors argue that this lends evidence to a basal ganglia dysfunction theory of the etiology of OCD. A case report by Laplane et al., (1981) follows this same thinking of infection causing damage to the basal ganglia with resultant $\mathrm{OC}$ behavior. Their patient developed obsessive-compulsive symptoms following a wasp sting which produced secondary necrosis of the basal ganglia.

\section{OBSESSIVE-COMPULSIVE SYMPTOMS ARISING IN THE SETTING OF METABOLIC DISORDERS}

In addition to OC symptoms associated with known infections or CNS lesions, there are many examples of obsessive-compulsive symptoms arising in the setting of other systemic neurologic disorders. George et al. (1989) reported a patient with multiple sclerosis and obsessivecompulsive disorder. The patient's cranial CT scan showed diffuse periventricular white matter lesions. Schwab et al. (1951) noted that many of their Parkinsonism patients, some of whom had post-encephalitic Parkinsonism, also had obsessive-compulsive disorder. Their obsessions were often sudden and paroxysmal and subsided after 15-30 min. Lees et al. (1989) recently reviewed the neurobehavioral abnormalities found in Parkinson's disease and concluded that there was a strong relationship between Parkinson's disease and some of the psychomotor retardation seen in obsessive-compulsive disorder.

\section{ANTECEDENT ILLNESS AND OCD}

Some authors have examined whether there is an increased rate of perinatal abnormalities in patients who develop obsessive-compulsive disorder. For example, Capstick and Seldrup (1977) compared 33 OCD patients to 33 psychiatric controls. Eleven OCD patients selfreported a history of abnormal birth, whereas only two from the other group gave a similar story. These findings are interesting, but hard to assess due to the problems of being retrospective self-report studies, with mixed psychiatric patients as controls.

\section{OC SYMPTOMS ASSOCIATED WITH EPILEPSY}

Some authors have remarked that many of the interictal personality changes seen in patients with temporal lobe epilepsy (TLE) resemble behaviors seen in obsessive compulsive disorder (Bear and Fidio, 1977; Blumer, 1975; Bruens, 1969; Waxman and Geschwind, 1975; Ciesielski et al., 1981; Epstein and Bailine, 1971). They proposed that obsessionalism might be a specific consequence of a repeatedly-firing temporal epileptic focus. Kettle and 


\begin{tabular}{llll}
\hline & & & References \\
\hline Lesions & Tumors & Temporal lobe & Brickner et al. (1940) \\
& & Seight Frontal et al. (1989) \\
& & Crontal & Cambier et al. (1988) \\
& Caudate & Tonkonogy and Barreira (1989) \\
Closed head injury & Striatum & Weilburg et al. (1989) \\
& & & McKeon et al. (1984) \\
Post-infectious & Host-encephalitic Parkinson's & & Hillbom (1960) \\
& Wasp sting & Schilder (1938) \\
& Von Economo's encephalitis & & Laplane et al. (1981) \\
& Sydenham's chorea & Wohlfart et al. (1961) \\
Others & Multiple sclerosis & Swedo (1989a, b) \\
& Parkinson's disease & George et al. (1989) \\
& Hypoglycemia & Schwab et al. (1951) \\
& Tourette's syndrome & Rippere (1984) \\
& & Gilles de la Tourette (1885) \\
& Perinatal complications & Lees et al. (1989) \\
& & Capstick and Seldrup \\
& Temporal lobe epilepsy & (1977) \\
& Diabetes insipidus & Bear and Fedio (1977) \\
& Manganese poisoning & Barton (1965) \\
& Amphetamine psychosis & Mena et al. (1967) \\
& & Ellinwood (1967)
\end{tabular}

Marks (1986) reported two cases of OCD developing in teenage patients soon after the onset of epilepsy. One woman with OCD had worsening obsessive-compulsive symptoms corresponding with increasing spike and wave discharges on her EEG (Gibson and Kennedy, 1960). Yaryura-Tobias and Neziroglu (1983) have described further cases of epilepsy with ictal or interictal OC symptoms.

To complete the survey, Barton (1965) noted that a patient with diabetes insipidus had obsessive-compulsive disorder. Rippere (1984) described two patients with hypoglycemia who had obsessive-compulsive symptoms. Obsessive-compulsive symptoms have also been reported in manganese poisoning (Mena et al., 1967) and amphetamine psychosis (Ellinwood, 1967; Koizumi, 1985).

\section{GILLES DE LA TOURETTE DISEASE}

By far the most imporant neurologic illness associated with obsessive-compulsive disorder is Gilles de la Tourette's syndrome (GTS) (Cummings and Frankel, 1985; Pitman et al., 1987; Robertson et al., 1988). The fundamental connection between obsessive-compulsive disorder and de al Tourette's was first recorded by Gilles de la Tourette (1885) who, in his original paper, noted that the Marquisa de D had obsessive-compulsive symptoms. The relation between obsessive-compulsive disorder and Tourette's has been neglected and rediscovered throughout recent neurologic history. Lees et al. (1984) recently reviewed this fundamental link. Reports of the comorbidity between OCD and GTS vary between $90 \%$ (Nee et al.,
1984), 67\% (Montgomery et al., 1982) and 51\% (Frankel et al., 1986). Recent genetic studies have shown that OCD and GTS may be different phenotypic expressions of the same gene (Pauls, 1986). Patients with OCD are known to have higher rates of tic and movement disorders. The occurrence of OCD and GTS within the same families, the clinical similarities between OCD and GTS, and the fact that both syndromes can stem from basal ganglia pathology argue that GTS and OCD might have similar neurobiological mechanisms.

\section{SUMMARY}

Obsessive-compulsive symptoms arise in conjunction with numerous neurologic illnesses (Grimshaw, 1964; Jenike, 1984; Ketti and Marks, 1986; Rapoport, 1988, 1989; Wexberg, 1938). Mass lesions or infarcts, particularly in the striatum or frontal or temporal lobes can cause OC symptomatology. There is an increased rate of obsessive-compulsive disorder in patients who have had closed head injury. Some infections (Sydenham's chorea, Von Economo's encephalitis, a wasp sting) cause secondary brain damage, particularly in the basal ganglia, which later results in obsessive-compulsive disorder. Obsessivecompulsive disorder patients self-report higher rates of previous neurologic illness. OCD also occurs with Parkinson's disease, multiple sclerosis, and most importantly, Gilles de la Tourette's syndrome. Additionally a fundamental link exists between Gilles de la Tourette's syndrome, tics, and obsessive compulsive disorder. Clearly, OCD can arise from focal neurologic disease (sympto- 
TABLE II. Neuroanatomic and neurophysiologic studies in OCD

\begin{tabular}{|c|c|c|}
\hline Study & Finding & Reference \\
\hline \multicolumn{3}{|l|}{ Imaging } \\
\hline CT & $\uparrow$ Caudate volume & Luxenburg et al. (1988) \\
\hline MRI & Prolonged $T_{1}$, in right frontal white matter & Garber et al. (1990) \\
\hline \multirow[t]{2}{*}{ PET } & $\uparrow$ Orbital-frontal metabolic rates & Baxter et al. (1988) \\
\hline & & Swedo et al. (1988a) \\
\hline \multicolumn{3}{|l|}{ Electrophysiological } \\
\hline \multirow[t]{2}{*}{ EEG } & $\begin{array}{l}\text { Left frontal dysfunction with power-spectral } \\
\text { analysis }\end{array}$ & Flor-Henry et al. (1979) \\
\hline & $\begin{array}{l}\text { 3/12 OCD with temporal sharp waves } \\
2 / 18 \text { OCD with abnormal EEG }\end{array}$ & $\begin{array}{l}\text { Jenike and Brotman (1984) } \\
\text { Insel et al. (1983) }\end{array}$ \\
\hline \multicolumn{3}{|l|}{ Electrical simulation studies } \\
\hline & $\begin{array}{l}\text { IStereotyped behavior with cingulate } \\
\text { stimulation }\end{array}$ & $\begin{array}{l}\text { Grey-Walter (1979) } \\
\text { Talairach et al. (1973) }\end{array}$ \\
\hline
\end{tabular}

matic OCD). But, what is happening in the brains of patients with idiopathic OCD, or OCD in the absence of detectable brain pathology?

\section{NEUROBIOLOGICAL STUDIES OF IDIOPATHIC OCD}

\begin{abstract}
Autopsy data
As yet, there have been no exhaustive studies of autopsy findings in OCD patients. This is partly due to the resurgence of interest in OCD and the lack, until recently, of good clinical criteria for the definition of the disease. A well-controlled autopsy study of properly diagnosed OCD patients would add immensely to our understanding.
\end{abstract}

\section{Imaging data}

Cranial CT scans on patients with idiopathic OCD are essentially normal with no pathognomonic lesion (Insel $e t$ al., 1983). However, a study by Luxenburg et al. (1988) showed decreased caudate nuclei volume in 10 OCD patients compared with controls. Garber et al. (1989) found that the spin lattice relaxation time $\left(T_{1}\right)$ for the right frontal white matter was prolonged on MRI scans of OCD patients compared with controls. Additionally, they found that right minus left $T_{1}$ differences in the orbital frontal cortex were strongly related to OCD severity. Kellner et al. (1991) failed to find any differences on MRI scans between OCD patients and a group of normal controls.

To date there have been at least three positron emission tomography (PET) studies of obsessive-compulsive disorder which have shown similar but not identical results (Baxter et al., 1988; Nordhal et al., 1989; Swedo et al., 1989b). Baxter et al. (1988) reported 10 OC subjects who showed increased absolute metabolic rate in the heads of the caudate nuclei and orbital gyri when compared to controls, using $f$-2-deoxy-2-fluro-D-glucose. In a second, more carefully designed study, Baxter et al. (1990) repli- cated this initial finding in 10 additional OCD subjects in a medication-free, age and sex matched controlled study. Only the orbital gyri metabolic rate was increased when compared to the ipsilateral hemisphere metabolic rate. Nordhal et al. (1989) reported that eight OCD subjects in an age- and sex-matched control study had increased glucose metabolic rates in their orbital gyri relative to the whole brain metabolic rate. Swedo et al. (1989b) described 18 childhood-onset OCD subjects in an age- and sex-matched controlled study. They found prefrontal and basal ganglia abnormalities in the OCD subjects, with elevated absolute glucose metabolism in the left orbital frontal, right sensory motor and bilateral prefrontal and anterior cingulate regions. The right prefrontal and left anterior cingulate regions showed relatively increased glucose metabolism. In addition, Swedo et al. reported a significant positive correlation between the right orbital glucose metabolic rate and the severity of the OCD.

In summary, most imaging modalities (some CT, MRI, and PET scans) indicate that in idiopathic OCD there are abnormalities in metabolism and underlying brain pathology in the caudate and orbital frontal gyri.

\section{EEG data}

Much of the EEG literature on OCD is dated and was performed when the diagnostic criteria for OCD were not clearly defined. Thus there are numerous reports of "abnormal" EEGs in OCD patients. However, it is difficult to decide how much weight to place on these studies. Flor-Henry et al. (1979) reported left frontal dysfunction in OCD under power spectral EEG analysis. These EEG data correlated with neuropsychological testing showing left frontal impairment in OCD patients. This data gives further weight to the theory that perturbations of the cingulate-orbital-frontal loop might modulate obsessive compulsive symptomatology. Insel et al. (1983) reported 2 of 18 OCD patients with abnormal EEGs. One patient had 


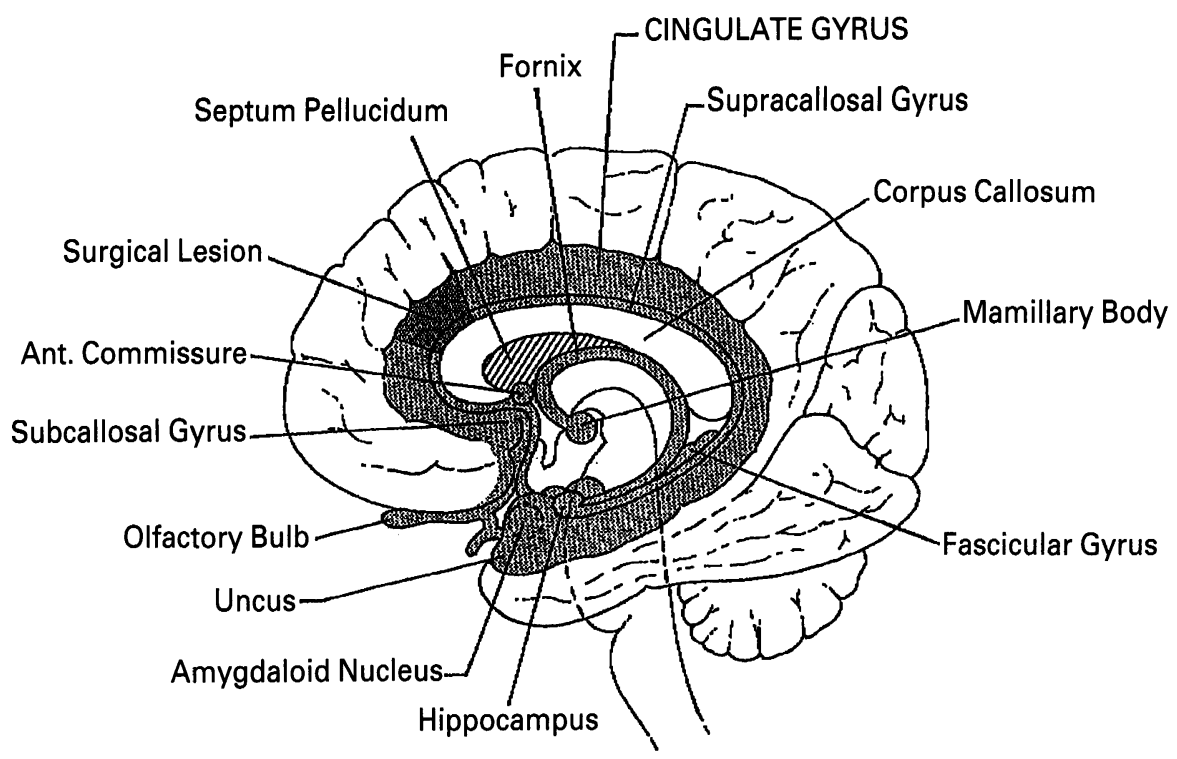

FIG. 1. Line drawing of the cingulum (cingulate gyrus), with the anterior portion highlighted.

left temporal sharp wave activity and the other had a predominance of beta activity over the left hemisphere. These patients' CT scans as a group were indistinguishable from matched non-psychiatric control subjects. Jenike (1984) reported on 3 of 12 patients with OCD who had temporal sharp wave activity. These three patients were tried on anti-seizure medications and only one improved. Thus far, EEG data in studies of OCD are inconclusive with several studies reporting mild temporal sharp wave activity in OCD patients.

\section{Psychosurgery}

Imaging data and case reports indicate that the cingulum, an area of the brain just dorsal to the corpus callosum, is intricately involved in obsessive-compulsive disorder (Fodstad et al., 1982; Tan et al., 1971) (see Fig. 1). GreyWalter (1979) reported the case of a university professor who was compelled to confess to local crimes and was cured when surgical lesions were placed in the cingulum. Grey-Walter theorized that overactivity of the cingulum therefore led to obsessive compulsive behavior. Talairach et al. (1973) reported 52 drug-resistant epileptics who had electrodes implanted while being examined for possible lobectomy for seizure management. These patients had stereotypic repetitive motions similar to compulsive rituals when the cingular region was electrically stimulated. Mitchell-Heggs et al. (1977) demonstrated that surgery with two small lesions in the cingulum and three small lesions in the lower medial frontal lobe resulted in clinical improvement in 24 of 27 obsessional patients. Recently, Tippin and Henn (1982) described five obsessional patients who improved with modified leukotomy and lesioning of the medial $2-3 \mathrm{~cm}$ of white matter coming through the anterior cingulate gyrus.

\section{UNIFYING THEORY OF THE NEUROBIOLOGY OF OCD}

OCD is a syndrome that may be caused by numerous central nervous system insults. Brain tumors and trauma to frontal and temporal regions, as well as basal ganglia infarcts, infections, or trauma can all cause symptomatic OCD. Imaging studies of OC patients without obvious neurologic causes (idiopathic OCD) have shown decreased caudate nuclei volume and hyperactivity of caudal-frontal regions. OCD, whether symptomatic or idiopathic, almost always involves dysfunction in the basal ganglia and frontal cortical projections.

There is an interesting correlation between OCD and diseases of the basal ganglia, particularly Gilles de la Tourette's syndrome (Devenport et al., 1981; Schneider, 1984). It remains to be seen what a putative OCD-Gilles de la Tourette's syndrome gene might do that would produce the symptoms seen in these disorders. Treatment with serotonergic agents such as fluoxetine (Fontaine and Chouinard, 1989; Jenike et al., 1989), fluvoxamine, and clomipramine (Insel et al., 1985; Pato et al., 1988) tend to decrease OC symptoms. Similarly, psychosurgery with lesions in the cingulum can markedly improve patients with refractory OCD.

A truly unified theory of the neurobiology of OCD remains to be found. An adequate theory must take into account the neuroanatomic data presented above where symptomatic OCD is cased by lesions in the caudate and 
orbital frontal gyri. It must additionally account for the known response of OCD patients to both antiserotonergic agents and psychosurgery involving lesions in the cingulum. Several authors have attempted putative theories (Baxter, 1990; McDougle et al., 1989; Modell et al., 1989). Baxter argues that the orbital cortex has been associated with the mediation of anxiety, with impulse control, and with meticulousness in hygiene. Using animal data, he also argues that behavioral inhibition and extinction as well as perseverative behaviors can be caused by stimulation or lesions of the orbital cortex. Because of the complex enervation of the striatum, pathology scattered throughout the striatum could produce different symptoms (tics, simple obsessive disorder, Gilles de la Tourette's syndrome) depending upon where the lesions are placed. This is an interesting theory which can theoretically be proved or disproved with available imaging techniques.

The neurosciences are at an exciting part of history. Imaging techniques such as MRI, PET, and SPECT will allow us to test putative hypotheses of the neurobiology of OCD and come to a better understanding of this interesting, complex and devastating human illness.

\section{REFERENCES}

American Psychiatric Association (1987). Diagnostic and Statistical Manual of Mental Disorders, 3rd Edn, revised. Washington, DC.

Barton, R. (1965). Diabetes Insipidus and obsessional neurosis: a syndrome. Lancet, 1, 133-135.

Baxter, L.R. (1990). Brain imaging as a tool in establishing a theory of brain pathology in obsessive-compulsive disorder. Journal of Clinical Psychiatry, 51 (Suppl.), 22-25.

Baxter, L.R., Schwartz, J.M., Guze, B.H., Bergman, K. and Szuba, M.P. (1990). PET imaging in obsessive-compulsive disorder with and without depression. Journal of Clinical Psychiatry, 51, 61-69.

Baxter, L.R., Schwartz, J.M., Maziotta, J.C. et al. (1988). Cerebral glucose metabolic rates in nondepressed patients with obsessive-compulsive disorder. American Journal of Psychiatry, 145, 1560-1563.

Bear, D.M., and Fedio, P. (1977). Quantitative analysis of interictal behavior in temporal lobe epilepsy. Archives of Neurology, 34, 454-467.

Blumer, D. (1975). Temporal lobe epilepsy and its psychiatric significance. In Psychiatric Aspects of Neurological Disease (Eds D.F. Benson and D. Blumer). Grune \& Stratton, New York.

Brickner, R.M., Rosner, A.A. and Munroe, R. (1940). Physiological aspects of the obsessive state. Psychosomatic Medicine, 2, 369-383.

Bruens, J.H. (1969). Psychoses in epilepsy. In Handbook of Clinical Neurology (Eds P.J. Vincker and A.W. Gruyn), Vol. 15, pp. 593-610. Wiley, New York.

Cambier, J., Masson, C., Benammous, S. and Robine, B. (1988). La graphomanie. Activite graphique compulsive manifestation d'un gliome fronto-calleux. Revue Neurologic, 144, 158-164.

Capstick, N. and Seldrup, J. (1977). Obsessional states: a study in the relationship between abnormalities occurring at the time of birth and subsequent development of obsessional symptoms. Acta Psychiatrica Scandinavica, 56, 427-431.

Ciesielski, K.T., Beech, H.R. and Gordon, P.K. (1981). Some electrophysiological observations of obsessional states. British Journal of Psychiatry, 138, 479-484.

Cummings, J.L. and Frankel, M. (1985). Gilles de la Tourette syndrome and the neurological basis of obsessions and compulsions. Biological Psychiatry, 20, 1117-1126.

Devenport, L.D., Devenport, J.A. and Holloway, F.A. (1981). Reward-induced stereotypy: modulation by the hippocampus. Science, 212; 1288-1289.

Epstein, A.W. and Bailine, S.H. (1971). Sleep and dream studies in obsessional neurosis with particular reference to epileptic states. Biological Psychiatry, 3, 149-158.

Ellinwood, E.H. (1967). Amphetamine psychosis: description of the individuals and the process. I. Journal of Nervous and Mental Disorders, 144, 273-283.

Flor-Henry, P., Yeudal, L.T., Koles, J.Z. and Howarth, B.G. (1979). Neuropsychological and power spectral EEG investigations of the obsessive-compulsive syndrome. Biological Psychiatry, 14, 119-130.

Fodstad, H., Strandman, E., Carlsson, B. and West, K.A. (1982). Treatment of chronic obsessive-compulsive states with stereotactive anterior capsulotomy or cingulotomy. Acta Neurosurgica, 62, 1-23.

Fontaine, R. and Chouinard, G. (1989). Fluoxetine in the longterm maintenance treatment of obsessive-compulsive disorder. Psychological Annals, 19, 88-91.

Frankel, M., Cummings, J.L., Robertson, M.M., Trimble, M.R., Hill, M.A. and Benson, D.F. (1986). Obsessions and compulsions in Gilles de la Tourette syndrome. Neurology, 36, 378-382.

Freud, S. (1959). Collected Papers, Vol III. Basic Books, New York.

Garber, H.J., Ananth, J.V., Chiu, L.C. et al. (1989). Nuclear magnetic resonance study of obsessive-compulsive disorder. American Journal of Psychiatry, 146, 1001-1005.

Gibson, J.G. and Kennedy, W.A. (1960). A clinical EEG study on a case of obsessional neurosis. Electroencephography and Clinical Neurophysiology, 12, 198-201.

George, M.S., Kellner, C.H. and Fossey, M.D. (1989). Obsessive-compulsive symptoms in a patient with multiple sclerosis. Journal of Nervous and Mental Diseases, 177, 304-305.

Gilles de la Tourette, G. (1885). Etude sur une affection nerveuse caractarisee par l'incoordination motrice accompagnee d'echolalic et de coprolalic. Archives Neurologie, 9, 19-42, 158-200.

Grey-Walter, W.G. (1979). Viewpoints of mental illness: neurophysiologic aspects. Seminars in Psychiatry, 14, 1.

Grimshaw, L. (1964). Obsessional disorder and neurological illness. Journal of Neurology, Neurosurgery and Psychiatry, 27, 229-231.

Hillbom, E. (1960). After effects of brain injuries. Acta Psychiatrica Neurologica Scandinavia, 35, (Suppl.), 42.

Husby, G., van de Ryn, I., Zabriskie, J.B. et al. (1976). Antibodies reacting with cytoplasm of subthalamic and caudate nuclei neurons in chorea and rheumatic fever. Journal of Experimental Medicine, 144, 1094-1110.

Insel, T.R., Donnelly, E.F., Lalakea, M.L., Alterman, I.S. and Murphy, D.L. (1983). Neurological and neuropsychological studies of patients with obsessive-compulsive disorder. Biological Psychiatry, 18, 741-751.

Insel, T.R., Mueller, E.A., Alterman, I., Linnoila, M. and Mur- 
phy, D.L. (1985). Obsessive-compulsive disorder and serotonin: is there a connection? Biological Psychiatry, 20, $1174-1188$

Jellife, S.E. (1929). Psychologic components in postencephalitic oculogyric crises. Archives of Neurology and Psychiatry, 21, 491-532.

Jenike, M.A. (1984). Obsessive-compulsive disorder: a question of neurologic lesion. Comparative Psychiatry, 25, 298-304.

Jenike, M.A., Baer, L. and Minichiello, W.E. (1986). ObsessiveCompulsive Disorders: Theory and Management, pp 171177. Yearbook Medical, Littleton, MA.

Jenike, M.A. and Brotman, A.W. (1984). The EEG in obsessivecompulsive disorder. Journal of Clinical Psychiatry, 45, 122-124.

Jenike, M.A., Buttolph, L., Baer, L., Ricciardi, J. and Holland, A. (1989). Open trial of fluoxetine in obsessive-compulsive disorder. American Journal of Psychiatry, 146, 909-911.

Kellner, C.H., Jolly, R.R., Holgate, R.C., Austin, L., Hydiard, R.B. and Laraia, M. (1991). Brain MRI in OCD. Psychiatry Resarch, 36, 45-49.

Kettle, P.A. and Marks, I.M. (1986). Neurological factors in obsessive-compulsive disorder: two case reports and a review of the literature. British Journal of Psychiatry, 149, 315-319.

Koizumi, H.M. (1985). Obsessive-compulsive symptoms following stimulants. Biological Psychiatry, 20, 1332-1337.

LaPlane, D., Widlocher, D., Pillon, B., Baulac, M. and Binoux, F. (1981) Comportement compulsif d'allure obsessionalle par necrose circonscite bilaterale pallido-striatale. Revue Neurologie, 137, 269-276.

Lees, A.J. (1989). The neurobehavioural abnormalities in Parkinson's disease and their relationship to psychomotor retardation and obsessive-compulsive disorders. Behavioural Neurology, 2, 1-11.

Lees, A.J., Robertson, M., Trimble, M.R. and Murray, N.M.F. (1989). A clinical study of Gilles de la Tourette's syndrome in the United Kingdom. Journal of Neurology, Neurosurgery, and Psychiatry, 47, 1-8.

Luxenberg, J.S., Swedo, S.E., Flament, M.F. et al. (1988). Neuroanatomic abnormalities in obsessive-compulsive disorder detected with quantitative X-ray computed tomography. American Journal of Psychiatry, 145, 1089-1093.

McDougle, C.J., Goodman, W.K., Delgado, P.L. and Price, L.H. (1989). Pathophysiology of obsessive-compulsive disorder. American Journal of Psychiatry, 146, 1350-1351.

McKeon. J., McGuffin, P. and Robinson, P. (1984). Obsessivecompulsive neurosis following head injury: a report of four cases. British Journal of Psychiatry, 144, 190-192.

Mena, I., Marik, O., Fuenzalida, S. and Cotzias, A.C. (1967). Chronic manganese poisoning. Neurology, 17, 128-136.

Mitchell-Heggs, N., Kelly, D. and Richardson, A.E. (1977). Stereotactic limbic glucotomy: clinical, psychological and physiologic assessment at sixteen months. In Neurosurgical Treatment in Psychiatry, Pain and Epilepsy (Eds Sweet and Obrador), pp. 367-379. University Park Press, Baltimore.

Modell, J.G., Mountz, J.M., Curtis, G.C. and Greden, J.F. (1989). Neurophysiologic dysfunction in basoganoglia/limbic striatal and thalamocortical circuits as a pathogenetic mechanism of obsessive-compulsive disorder. Journal of Neuropsychiatry, 1, 27-36.

Montgomery, M.A., Clayton, P.J. and Friedhoff, A.J. (1982). Psychiatric illness in Tourette syndrome patients and firstdegree relatives. In Gilles de la Tourette Syndrome (Eds A.J. Freidhoff and T.N. Chase), pp. 335-339. Raven Press, New York.
Nordahl, T.E., Benkelfet, C., Semple, W.E. et al. (1989). Cerebral glucose metabolic rates in obsessive-compulsive disorder. Neuropsychopharmacology, 2, 23-28.

Nee, L.E., Caine, E.D., Polinsky, R.J., Eldridge, R. and Ebert, M.H. (1984). Gilles de la Tourette syndrome in the United Kingdom. Journal of Neurology and Neurosurgical Psychiatry, 47, 1-8.

Pato, M.T., Zohar-Kadouch, R., Zohar, J. and Murphy, D.L. (1988). Return of symptoms after discontinuation of clomipramine in patients with obsessive-compulsive disorder. American Journal of Psychiatry, 45, 1521-1525.

Pauls, D.L., Towbin, K.E., Leckman, J.F., Zahner, G.E.P. and Cohen, D.J. (1986). Gilles de la Tourette syndrome and obsessive-compulsive disorder. Archives of General Psychiatry, 43, 1180-1182.

Pitman, R.K., Green, R.C., Jenike, M.A. and Mesulam, M.M (1987). Clinical comparison of Tourette's disorder and obsessive-compulsive disorder. American Journal of Psychiatry, 144, 1166-1171.

Rapoport, J.L. (1989). The biology of obsessions and compulsions. Scientific American, 3, 83-89.

Rapoport, J.L. (1988). The neurobiology of obsessive compulsive disorder. Journal of the American Medical Association, 260, 2888-2889.

Ripperre, V. (1984). Can hypoglycemia cause obsessions and ruminations? Medical Hypotheses, 15, 3-13.

Robertson, M.M., Trimble, M.R. and Lees, A.J. (1988). The psychopathology of Gilles de la Tourette syndrome: a phenomenological analysis. British Journal of Psychiatry, 152, 283-390.

Robins, L.N., Helzer, I.I., Weissman, M.M. et al. (1984). Lifetime prevalence of specific psychiatric disorders in three sites. Archives of General Psychiatry, 41, 949-958.

Schilder, P. (1938). The organic background of obsessions and compulsions. American Journal of Psychiatry, 94, 1398-1413.

Schneider, J.S. (1984). Basal ganglia role in behavior: importance of sensory gauging and its relevance to psychiatry. Biological Psychiatry, 19, 1693-1710.

Schwab, R.S., Fabing, H.D. and Prichard, J.S. (1951). Psychiatric symptoms and syndromes in Parkinson's disease. American Journal of Psychiatry, 107, 901-907.

Seibyl, J.P., Krystal, J.H., Goodman, W.K. and Price, L.H. (1989). Obsessive-compulsive symptoms in a patient with a right frontal lobe lesion. Neuropsychiatry, Neuropsychology, and Behavioral Neurology, 1, 295-299.

Swedo, S.E., Rapoport, J.L., Cheslow, B.S. et al. (1989a). High prevalence of obsessive-compulsive symptoms in patients with Syderham's chorea. American Journal of Psychiatry, 146, 246-249.

Swedo, S.E., Shapiro, M.B., Grady, C.L. et al. (1989b). Cerebral glucose metabolism in childhood onset obsessive-compulsive disorder. Archives of General Psychiatry, 46, 518-523.

Talairach, J., Bancaud, J., Geir, S. et al. (1973). The cingulate gyrus in human behaviour. Electroencephalography and Clinical Neurophysiology, 34, 45-52.

Tan, E., Marks, I.M. and Marset, P. (1971). Bimedial leucotomy in obsessive-compulsive neurosis: a controlled serial enquiry. British Journal of Psychiatry, 118, 155-164.

Tippin, J. and Henn, F.A. (1982). Modified leukotomy in the treatment of intractable obsessional neurosis. American Journal of Psychiatry, 139, 1601-1603.

Tonkonogy, G.A. and Barriera, P. (1989). Obsessive-compulsive disorder and caudate-frontal lesion. Neuropsychiatry, 
Neuropsychology and Behavioral Neurology, 2, 203-209.

Waxman, S.G. and Geschwind, N. (1975). The interictal behavior syndrome of temporal lobe epilepsy. Archives of General Psychiatry, 32, 1580-1586.

Weilburg, J.B., Mesulam, M.M, Weintraub, S. et al. (1989). Focal striatal abnormalities in a patient with obsessive-compulsive disorder. Archives of Neurology, 46, 233-235.

Wexberg, E. (1938). Comments on the organic background of obsessions and compulsions. American Journal of Psychiatry, 94, 1415-1416.

Wohlfart, G., Ingvar, D.H. and Gelberg, A.M. (1961). Compulsory shouting (Benedek's "klazomania") associated with oculogyric spasms in chronic epidemic encephalitis. Acta Psychiatrica Scandinavia, 36, 369-377.

Yaryura-Tobias, J.A. and Nezirogm, F.A. (1983). ObsessiveCompulsive Disorders. Marcel Dekker, New York. 


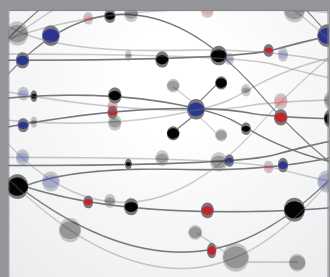

The Scientific World Journal
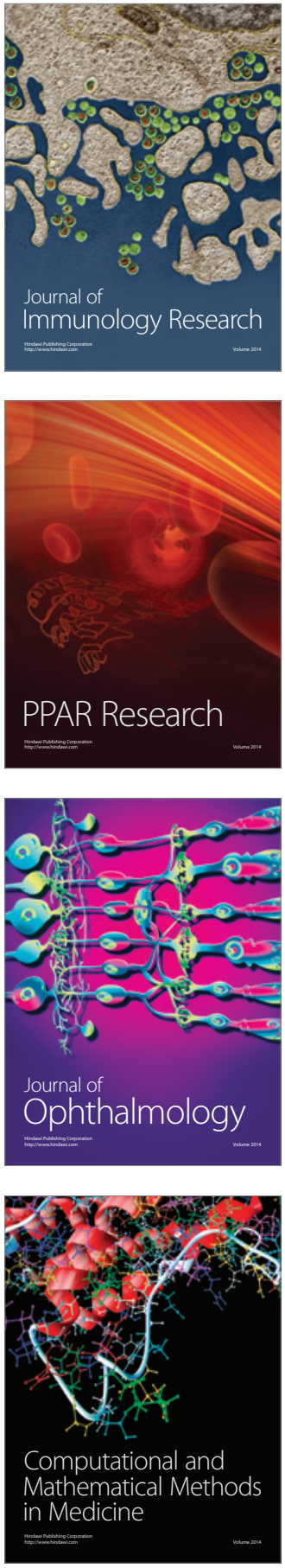

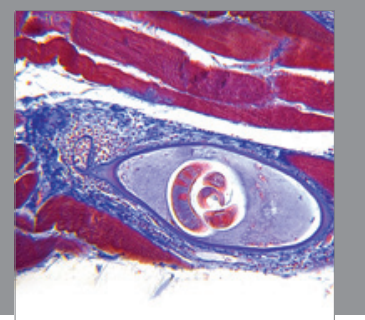

Gastroenterology

Research and Practice
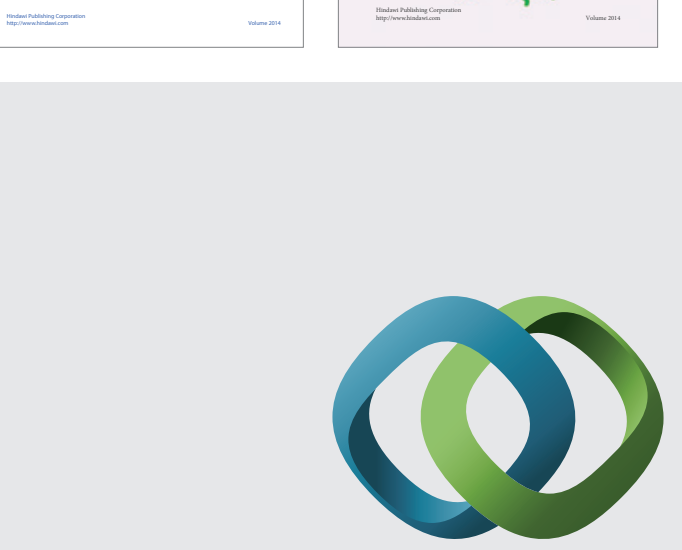

\section{Hindawi}

Submit your manuscripts at

http://www.hindawi.com
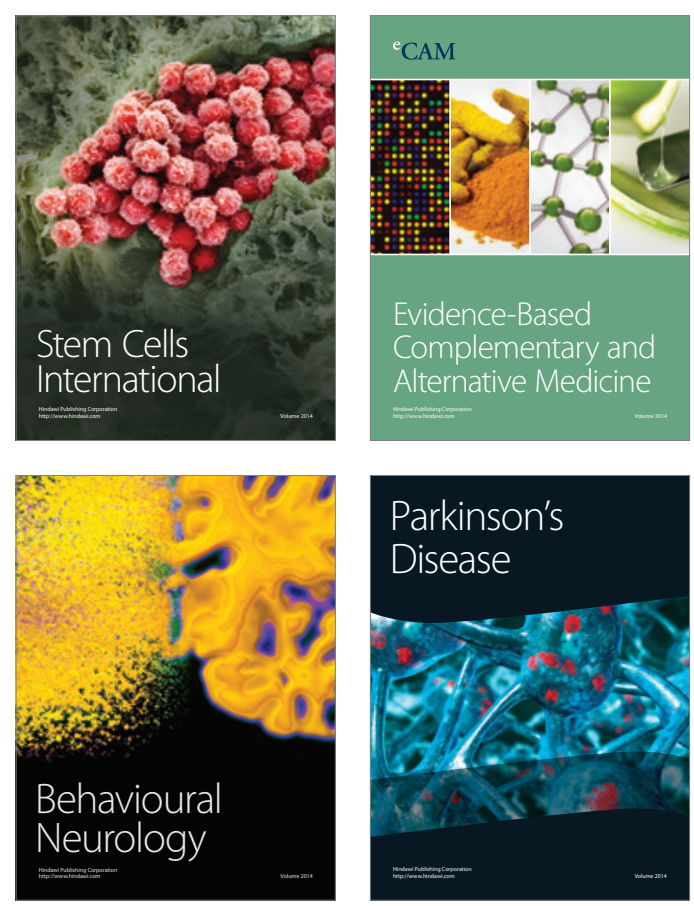

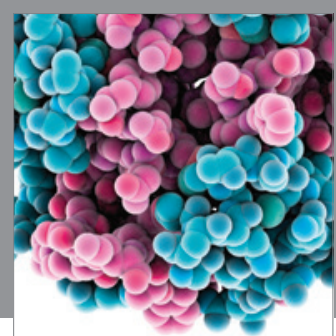

Journal of
Diabetes Research

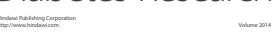

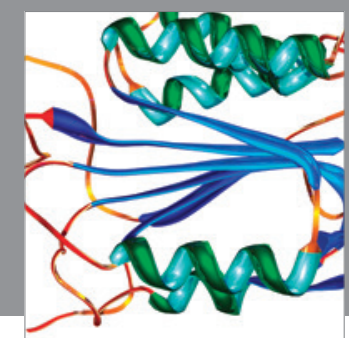

Disease Markers
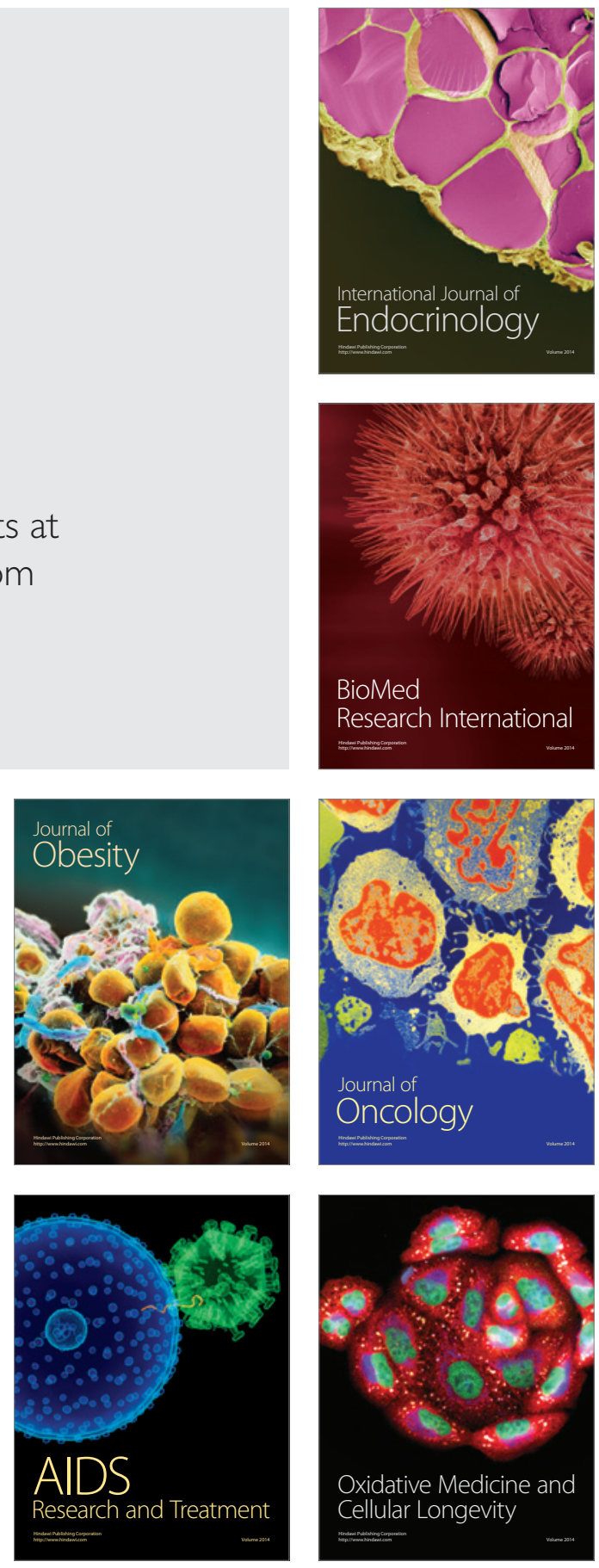